\title{
NOVA GESTÃO PÚBLICA NA NORUEGA: O PAPEL DO CONTEXTO NACIONAL NA MEDIAÇÃO DA REFORMA EDUCACIONAL
}

\author{
Jorunn MøLler \\ GuRI SKEDSMO*
}

\begin{abstract}
RESUMO: Desde o final dos anos 1980, o sistema educacional norueguês passou por grandes reformas amplamente influenciadas pelas novas ideias gerencialistas. As estratégias para renovar o setor público foram promovidas com a nova gestão pública (NGP). Este artigo investiga a forma pela qual as ideias ligadas às reformas da NGP foram introduzidas e interpretadas no setor educacional norueguês. Com base em nossos estudos de documentos de políticas públicas selecionados, de um período que compreende as últimas duas décadas, identificamos três áreas de luta discursiva. A primeira está vinculada a ideologias e à história nacional de escolarização; a segunda está relacionada a assuntos debatidos no que tange ao profissionalismo docente e, a terceira, está associada às estratégias de modernização e melhoria da educação. Um argumento central é que as reformas da NGP mudaram de direção e foram aceleradas quando a Noruega foi listada entre os países com "baixo desempenho" de acordo com o Pisa e outros testes internacionais. A liderança e a responsabilização (accountability) se tornaram os temas dominantes no campo da educação norueguesa.
\end{abstract}

Palavras-chave: Nova gestão pública; Liderança escolar; Prestação de contas; Profissionalização do professor; Noruega.

\section{NEW PUBLIC MANAGEMENT IN NORWAY: THE ROLE OF NATIONAL CONTEXT IN MEDIATING EDUCATIONAL REFORM}

ABSTRACT: Since the end of the 1980s the Norwegian education system has gone through major reform, largely influenced by new managerialist ideas. Strategies to renew the public sector were promoted as the new public management (NPM). This paper investigates the way ideas connected to NPM reforms have been introduced and interpreted in the Norwegian education sector. Based on our studies of

* University of Oslo, Faculty of Educational Sciences, Department of Teacher Education and School Research. Oslo, Norway. E-mail de contato: jorunn.moller@ils.uio.no. 
selected policy documents from the last two decades, we have identified three areas of discursive struggle. The first one is linked to ideologies and the national history of schooling, the second to contested issues of teacher professionalism and the third is associated with strategies for modernising and improving education. A main argument is that NPM reforms changed direction and sped up when Norway was listed among the 'lower-performing' countries according to Pisa and other international tests. Leadership and accountability became the dominant themes in Norwegian education.

Keywords: NPM reform; School leadership; Accountability; Teacher professionalism; Norway.

\section{NOUVELLE GESTION PUBLIQUE EN NORVÈGE : LE RÔLE DU CONTEXTE NATIONAL DANS LA MÉDIATION DE RÉFORME DE L'ÉDUCATION}

RÉSUMÉ: Depuis la fin des années 1980, le système éducatif norvégien a subi d'importantes réformes largement influencées par de nouvelles idées de gestion. Les stratégies visant à renouveler le secteur public ont été divulguées comme la nouvelle gestion publique (NGP). Cet article examine la façon dont les idées liées aux réformes NGP ont été présentées et interprétées dans le secteur de l'éducation norvégienne. Basés sur nos études de documents sélectionnés de la politique publique, d'une période comprenant les deux dernières décennies, nous avons identifié trois domaines de lutte discursive. Le premier est lié aux idéologies et à l'histoire de l'éducation nationale ; le deuxième est lié aux questions examinées en ce qui concerne le professionnalisme des enseignants et le troisième est associé aux stratégies de modernisation et à l'amélioration de l'éducation. Un argument central est que les réformes de la NGP ont changé de direction et se sont accélérées lorsque la Norvège a été classée parmi les pays à "faible performance" selon le Pisa et d'autres tests internationaux. Le leadership et la responsabilité (accountability) sont devenus les thèmes dominants dans le domaine de l'éducation norvégienne.

Mots-clés: Nouvelle gestion publique; Leadership scolaire; Responsabilisation; Professionnalisme des enseignants; Norvège.

\section{Introdução $^{1}$}

abordagem dos países em relação à reforma educacional é cultural e
historicamente distinta. Ao mesmo tempo elas parecem, no presente,
ser conjugadas por forças econômicas e políticas em comum, e ten- 
as últimas décadas, novas políticas influenciadas pelo gerencialismo têm tentado reestruturar a provisão da educação nos países do mundo Ocidental. Essas políticas geralmente almejam reduzir os gastos públicos, bem como a estrutura burocrática, estimulando a competição e a mercantilização dos serviços públicos, monitorando a eficiência e a eficácia por meio da mensuração de resultados e do desempenho dos servidores, e tentando alterar os regimes e as culturas das instituiçóes públicas de forma que se assemelhem mais estreitamente àquelas encontradas em negócios visando lucros (POLLITT; BOUCKAERT, 2004; CHRISTENSEN; LÆGREID, 2007). A ideia subjacente é que as instituições do setor público não são diferentes de empreendimentos que visam lucros e que não há nada diferenciado na gestão da educação. (PETERS; PIERRE, 2005).

Nos anos 1990, estratégias para renovar o setor público foram promovidas como reformas da nova gestão pública (NGP). Pesquisadores apontaram as características em comum dessas reformas. Além do ethos empresarial mencionado acima, eles incluem desregulamentação, descentralização e flexibilização organizacional. No âmbito organizacional, há uma ênfase na liderança empresarial, em recompensas econômicas e sanções, e um movimento que desvia o foco de regras e processos e centra-se em objetivos e resultados. (KLAUSEN, 2001; PETERS; PIERRE, 2005) Políticos e administradores em vários países têm considerado tais características como ingredientes vitais na renovação do setor público em geral, incluindo a educação. No entanto, as variaçóes em como os elementos políticos têm sido implementados ou incorporados atestam que o contexto cultural da reforma é um aspecto importante, e que o sucesso na aplicação das estratégias da NGP em uma instituição pública possui grande relação com a compatibilidade cultural. Se houver um nível grande de consistência com os valores subjacentes às reformas, é mais provável que as reformas sejam adotadas. (OZGA; JONES, 2006; CHRISTENSEN; LÆGREID, 2007) Embora as estratégias pareçam ser universais, e geralmente se atribua que se originam de uma única fonte de tendências neoliberais, estudos mostram como elas têm assumido variados formatos em diferentes países, devido aos diferentes processos de adaptação contextual. (HOOD, 2007; CHRISTENSEN; LÆGREID 2011) Durante o processo de tradução, as políticas são repetidamente reinterpretadas, reflexionadas e reagrupadas, o que significa que devemos prestar atenção às conjunturas locais nas quais as ideias são recebidas, traduzidas, mediadas e adaptadas em novas práticas. (CLARKE; NEWMAN, 2009)

Este artigo investiga, portanto, de que forma as ideias ligadas às reformas da NGP foram introduzidas e interpretadas no setor educacional na Noruega. Uma questão-chave para exploração é: como essas ideias são traduzidas e adaptadas de forma a se alinhar com as normas e valores existentes no sistema educacional norueguês. Em particular, discutiremos as mudanças na forma pela qual as responsabilidades da governança e liderança locais são concebidas em documentos 
políticos-chave. Nossa análise se apoia, principalmente, na análise textual dos documentos selecionados. Dois White Papers escritos com 13 anos de intervalo se destacam como documentos-chave por meio dos quais podemos ver a trajetória das mudanças na governança da educação: o White Paper n. 37 (1990-1991) e o White Paper n. 30 (2003-2004). Além disso, a discussão se embasa na análise de outros documentos relevantes que estão ligados a esses dois.

A primeira parte deste artigo descreve as características principais do sistema educacional norueguês, tais como a sua abrangência, que está associada ao sistema público do bem-estar social; os valores fundamentais, tais como igualdade e justiça, participação e democracia; as características vinculadas à relação entre os principais atores governamentais no sistema educacional. Tais características servirão de base para discutir como o novo gerencialismo tem sido interpretado no contexto da educaçáo norueguesa. A segunda parte expóe como as novas ideias gerencialistas têm sido introduzidas e moldadas em um sistema de escolaridade compulsória. A isso se segue uma discussão das relações entre as novas ideias gerencialistas e as mudanças na forma como a governança e a liderança da escola local são representadas nos documentos de políticas públicas.

\section{Características-chave da educação norueguesa}

O sistema educacional norueguês é predominantemente público, o que significa que as autoridades do Estado gerem a maioria das escolas e universidades. A educação é gratuita em todos os níveis. Não há divisão de acordo com habilidades, gênero ou outros fatores, e mais de $95 \%$ dos alunos noruegueses estão matriculados em escolas regulares. Isso se baseia na ideologia de que todas as crianças, independentemente de deficiência física ou mental ou dificuldade de aprendizagem, deve ser integrada o máximo possível no sistema escolar regular. A população é dispersa e muitas das escolas são bem pequenas. Em 2011, quase metade dos alunos na educação obrigatória (46\%) frequentavam escolas com menos de 300 alunos, mas essa percentagem vem diminuindo a cada ano, e muitas escolas pequenas foram fechadas nos últimos cinco anos (The Norwegian Directorate of Education and Training 2011).

A igualdade e a justiça são reconhecidas como uma das características distintivas do modelo educacional norueguês. $\mathrm{O}$ conceito de igualdade e justiça na educação fundamental na Noruega tem ao menos três sentidos. O primeiro é igual acesso ao sistema educacional. A justiça é compreendida como responsabilidade do sistema educacional em distribuir recursos financeiros de forma a ir ao encontro das necessidades de todos os usuários de uma maneira que forneça oportunidades iguais. O segundo sentido possui relação com a igualdade em nível individual. Este responde à diversidade entre os alunos e, portanto, à necessidade de trata- 
mento individualizado para atender as habilidades individuais de aprendizagem. O terceiro sentido concerne a equidade no âmbito do grupo. Por exemplo, alunos com línguas de minoria têm o direito coletivo de receber instrução linguística adicional. (MØLLER; SKEDSMO, 2013)

Não apenas essa ideologia deu lugar a um sistema educacional abrangente, mas também a um sistema público, de bem-estar social, configurado de forma a garantir ajuda em fases difíceis da vida (por exemplo, doença, incapacidade ou desemprego temporário). Esse sistema também inclui o empenho em relação ao pleno emprego e uma diminuição das desigualdades em termos de renda e gênero. (ESPING-ANDERSEN, 1990; ANTIKAINEN, 2006) Também há, na Noruega, uma forte tradição ideológica de se enfatizar o papel das instituiçóes educacionais na criação da sociedade civil. Além de preparar as crianças para se tornarem funcionários capazes, as escolas devem prepara-las para desempenhar papéis construtivos em uma sociedade democrática. Isso implica que uma das principais responsabilidades do diretor da escola, dos professores e de todos aqueles que trabalham nas escolas é enfocar a promoção da equidade e justiça social na escola, bem como na comunidade mais ampla. (MØLLER, 2006)

Embora a regulamentação por parte do Estado tenha sido importante na construção de um sistema educacional abrangente após a Segunda Guerra Mundial, a descentralização tem sido mais dominante como uma estratégia de reforma no setor público desde os anos 1980 e tem sido concebida como uma estratégia para a melhoria da qualidade. Comparada a outros países, a Noruega possui um setor público muito amplo, e os municípios e condados desempenharam, e ainda desempenham, um papel forte na governança da escola. ${ }^{2} \mathrm{~A}$ responsabilidade de liderança no âmbito municipal e do condado é compartilhada entre administradores profissionais e políticos eleitos. Por meio deste vínculo, a educação está conectada a assuntos mais amplos da comunidade. (ENGELAND, 2000) Atualmente os municípios são retratados como "os proprietários" da maioria das escolas; eles financiam suas escolas e empregam professores. Eles também desempenham um papel-chave no fornecimento de treinamento em serviço para os professores e dirigentes escolares.

Ao mesmo tempo, o Sistema de Avaliação da Qualidade Nacional (NQAS), que foi introduzido em conjunto com a reforma do currículo - a Promoção do Conhecimento (Knowledge Promotion - K06) -, implica em aumento da regulação central, pois possibilita que as autoridades nacionais retenham algum controle sobre os resultados, por meio da mensuração e avaliação de resultados educacionais. Esses resultados, então, lançam as premissas para o aprimoramento e desenvolvimento futuros. (SKEDSMO, 2009) Isso pode ser descrito como uma guinada nas políticas educacionais norueguesas: do uso de instrumentos de políticas públicas orientadas pelo insumo, para instrumentos mais orientados 
por resultados. As informaçóes fornecidas pelo NQAS oferecem uma base para o desenvolvimento de políticas centrais, para a coordenação e a gestão.

$\mathrm{Na}$ maioria dos municípios os professores gozam de considerável confiança e autonomia, e as relaçóes entre os dirigentes e os professores não são muito hierárquicas na prática. A Noruega também possui uma longa tradição de democracia no ambiente de trabalho, na qual sindicatos resilientes têm desempenhado papéis importantes. Recentemente, novas construçóes do profissionalismo docente têm sido produzidas tanto pelo governo quanto pelo sindicato dos professores, indicando ideias contrastantes de profissionalismo docente em um contexto de crescente responsabilização. Os documentos políticos enfatizam a necessidade de controlar a competência e os resultados dos professores. A responsabilidade do professor tem sido restringida e é articulada, principalmente, em termos de responsabilidade pelos resultados alcançados. Em contraste, o sindicato dos professores destaca a adoção, pelos professores, da responsabilidade pela qualidade da educação nas escolas. Embora o sindicato aborde aspectos do profissionalismo docente, ele não é específico em relação a alternativas de mecanismos de controle externos. (MAUSETHAGEN; GRANLUND, 2012)

\section{Perspectivas teóricas e métodos de pesquisa}

A relação entre o Estado, as autoridades educacionais locais e as escolas é central para compreender a forma como as reformas da NGP têm sido interpretadas no setor educacional norueguês. $\mathrm{O}$ controle do Estado reside na capacidade do governo em formular, ganhar a adesão e implantar políticas por meio de regulamentações e ferramentas de governança, ao passo que a influência das autoridades locais depende de como a política é interpretada e levada a cabo localmente.

Os elaboradores de políticas públicas geralmente traçam fronteiras entre o que é ou não uma reforma, para separar as práticas esperadas de outras. Determinadas práticas são incluídas como parte da reforma e outras são excluídas. No entanto, essas fronteiras não são fixas, mas negociadas, e elas podem mudar de acordo com o tempo e o espaço. (NESPOR, 2002) Além disso, as expectativas orientadoras são frequentemente ambíguas e, portanto, sujeitas a interpretação, debates e disputas no âmbito da escola.

Neste artigo, nossa lente analítica é inspirada por teorias institucionais que enfatizam que as açóes e atividades não podem ser vistas como o resultado de cadeias lineares de decisão, do nível central para o local. Ao contrário, elas são construçôes emergentes de vários atores que traduzem novas demandas e iniciativas em culturas estabelecidas no sistema educacional. (MAHONEY; THELEN, 2010) Este estudo objetiva investigar como as estratégias da NGP foram 
construídas em dois documentos-chave produzidos pelo Ministério da Educação e Pesquisa. Esses White Papers foram selecionados porque servem como pontos de referência para futuras políticas educacionais e como base para legislação futura. A análise é essencialmente textual, sendo que ambos enfocam a governança do sistema educacional. Nosso interesse é a linguagem utilizada nesses documentos.

No primeiro documento, o White Paper n. 37 (1990-1991), que se autodescreve como "sobre a organização e a gestão do setor educacional", foi escolhido devido a ter introduzido e adaptado o conceito de gestão orientada por objetivos e resultados ao setor educacional na Noruega. O segundo documento, o White Paper n. 30 (2003-2004), que se autodescreve como sendo a respeito da "cultura para a aprendizagem", foi publicado 13 anos depois e selecionado porque descreve de forma mais detalhada as ideias relacionadas com a Nova Gestão Pública (NGP) e o NQAS. Outros documentos relevantes foram produzidos durante o intervalo entre a publicação desses dois documentos, ou até antes do primeiro documento; todos eles realizaram um movimento de vai e vem em relação ao discurso sobre a NGP. Como tais, os documentos podem ser compreendidos como o resultado de negociações políticas contínuas.

Em nossa análise, a linguagem é tratada como uma prática social: uma maneira de agir. A análise aqui apresentada objetiva explorar os efeitos sociais das interpretaçóes da linguagem das políticas públicas, à qual os atores-chave no sistema escolar são convocados a subscrever (BALL, 1994); ao mesmo tempo, este artigo também tenciona questionar esses significados. A abordagem metodológica aqui utilizada inspira-se na análise crítica do discurso, que define o discurso como "[...] uma prática não apenas de representar o mundo, mas de fazê-lo significar, constituindo e construindo o mundo com base em significados [...]”. (FAIRCLOUGH, 1992, p. 62) Por meio da argumentação, pode ser possível descobrir fatores constitutivos e reguladores que mostram como a governança local e as responsabilidades da liderança são representadas nesses documentos. Foi proveitoso explorar as distinçóes entre construir sentidos sobre o texto como um todo e dividi-lo em categorias de descontextualização e recontextualização.

Fundamentamo-nos na leitura cuidadosa dos documentos, seguindo três etapas (SØREIDE, 2007; MAUSETHAGEN; GRANLUND, 2012): a primeira leitura objetivou obter uma visão geral, identificar como a reforma da gestão da educação é contextualizada em relação a problemas específicos e como os documentos propagam uma versão específica de um problema público reconhecido e o atrelam à solução defendida; a segunda leitura centrou-se em palavras e grupos de palavras usados para descrever os aspectos-chave do sistema de governança; a terceira leitura incluiu uma comparação entre as construçóes sobre a gestão do setor educacional, com o intuito de identificar possíveis mudanças discursivas nos textos das políticas. ${ }^{3}$ 
Em relação a esses documentos, nós também nos referiremos à revisão do sistema educacional norueguês conduzida pela Organização para a Cooperação e Desenvolvimento Econômico (OCDE), em 1988. Esse relatório foi o ponto de partida para um debate sobre as estratégias de governança que conduziram à publicação do White Paper n. 37 (1990-1991). Também comentaremos as alteraçóes no Ato da Educaçáo, regulamentaçóes no setor municipal e três documentos curriculares nacionais: o Currículo Nacional de 1987 (M87); o Currículo Nacional para o Ensino Obrigatório de 10 anos na Noruega, de 1997 (L97); e a Promoção do Conhecimento de 2006 (K06). Esses documentos foram decididos pelo Parlamento e, como tal, são indicativos dos sistemas de valores que operam no discurso educacional da Noruega. Além disso, nossa discussão é informada por estudos empíricos e análises da implantação das reformas educacionais e das novas ideias gerencialistas.

\section{A nova gestão pública na Noruega}

\section{A primeira onda: a Modernização por meio da Descentralização e a Gestão por Objetivos}

A mudança emergente em direção à NGP na Noruega foi iniciada pelo governo de coalizão Conservador com um programa de modernização em 1986. Este programa trouxe ideias sobre a delegação estrutural, especialização horizontal, eficiência e princípios de gestão. Em 1987, houve uma mudança no governo, e o Partido Trabalhista tomou posse, mas o novo governo continuou o programa de modernização ao longo das mesmas linhas. Numerosos programas foram lançados desde então por vários governos, pressionando por reformas no setor público, mas que tendem a ser coleçóes desconexas das ideias da reforma. As comissóes públicas, incluindo os peritos e os representantes dos sindicatos de servidores (especialmente quando o Partido Trabalhista estava no poder), também desempenharam seu papel ao pressionar por reformas no setor público, (HANSEN, 2011)

A versão norueguesa da NGP incluiu mais ênfase na descentralização e delegação de tarefas e foi acompanhada pela introdução da Gestão por Objetivos (GPO) como um sistema de governança. (CHRISTENSEN, 1991) Os atores centrais envolvidos, no processo de interpretação e adaptação da GPO, foram a consultoria pública "Statskonsult", a consultoria privada, instituiçóes públicas e comitês de trabalho indicados para investigar os problemas relacionados ao estabelecimento da GPO, como um novo sistema de governança.

No setor educacional, a GPO surgiu na M87 (Currículo Nacional de 1987) como um princípio norteador. (SIVESIND, 2008) Este documento também enfatizou a responsabilidade das escolas e municípios em desenvolver o 
currículo local com base nos objetivos nacionais, a avaliação escolar e o desenvolvimento local. Em 1988, a OCDE conduziu uma revisão do sistema educacional norueguês. Foram levantadas questóes acerca de como as autoridades centrais poderiam formar uma opinião acerca do nível de qualidade em um sistema escolar tâo fortemente descentralizado e influenciar seu nível de qualidade. (OECD, 1988) Os avaliadores enfatizaram que sua preocupação não era reintroduzir um controle nacional, mas considerar formas pelas quais "as boas normas da prática educacional” (OECD, 1988, p. 46) poderiam ser estabelecidas e disseminadas. Isso requeria que mais atenção fosse dada aos processos educacionais e seus resultados.

Várias iniciativas do Estado vieram em resposta às questóes levantadas pelos avaliadores da OCDE. O White Paper n. 37 (1990-91) introduziu a GPO formalmente como o novo sistema de governança na educação e delineou a divisão de tarefas e responsabilidades para os vários níveis do sistema educacional. (GUNDEM, 1993; KARLSEN, 1993) O objetivo geral era conseguir uma administração educacional racional e apropriada com o mais alto nível possível de coordenação e consistência entre os vários níveis de gestão e esferas educacionais. (White Paper n. 37, 1990-91) As estruturas do setor educacional à época foram caracterizadas como sendo extremamente divididas e inflexíveis. A divisão de tarefas e responsabilidades, em nível nacional, foi descrita como não sendo clara e a governança pelo Estado como difícil devido à falta de coordenação e consistência. Como consequência, os sinais de governança por parte do Estado não eram claros e isso conduzia à isenção de responsabilidade por todo o sistema educacional. Além disso, argumentou-se que "[...] as regulamentaçóes pelo Estado haviam se tornado tão detalhadas que ameaçavam a autonomia local [...]". (White Paper n. 37, 1990-91, p. 19)

A GPO foi proposta nesse White Paper como a solução para os problemas mencionados acima relacionados à governança e coordenação. (SKEDSMO, 2009) Um sistema nacional de avaliação e documentação foi apresentado como a premissa para a introdução da GPO e como "uma condição central para a autonomia local”. (White Paper n. 37, 1990-91, p. 26) Com relação à descentralização de tarefas e da responsabilidade, o White Paper acentuou que cabia ao Estado a responsabilidade geral pelo sistema, mas que o Estado não seria responsável por decisóes relativas a áreas cuja responsabilidade havia sido transferida. O White Paper traçava uma diferenciação entre a responsabilidade pelo sistema, que implicava a supervisão do sistema educacional e em que medida os objetivos nacionais eram seguidos, e a responsabilidade pelos resultados alcançados. (MØLLER; SKEDSMO, 2013)

Com base nesse White Paper, um Ato do Governo Local foi promulgado em 1992 e, como consequência, muitos municípios reestruturaram seu modelo organizacional, diminuindo os níveis administrativos de três para dois, entre o final dos anos 1990 e início dos anos 2000. (TRANVIK; FIMREITE, 2006) O 
argumento exposto foi de que o projeto de Estado do bem-estar (welfate-State) havia transformado a autoridade local em organizaçóes burocráticas, com pouca capacidade de resposta. O objetivo da reestruturação era aumentar a autonomia local, introduzir a transferência da estrutura e a especialização horizontal e, por meio disso, achatar as hierarquias municipais e desenvolver a entrega de serviços públicos de forma mais individualizada e eficiente. (HOMME, 2008; HANSEN, 2011) Os princípios apresentados no White Paper n. 37 (1990-91) se manifestaram no desenvolvimento de novas diretrizes para o currículo nacional para o ensino fundamental e médio, a começar pelo Currículo Central em 1993 (L93). Este quadro curricular geral foi seguido de novas diretrizes abrangentes para o ensino pós-secundário em 1994 (Reforma 94) e para as escolas de ensino fundamental I e II em 1997 (L97). Juntamente com o discurso emergente da NGP, que influenciava a reestruturaçáo do setor público, os objetivos dessas diretrizes curriculares foram formuladas de acordo com as ideias influenciadas pela GPO. (GUNDEM, 1993) As reformas foram acompanhadas de iniciativas para desenvolver uma avaliação baseada nas escolas e guiada por pares. Essas formas de avaliação focalizavam principalmente os processos e desenvolvimento internos, por exemplo, a instrução do professor e sua interação com os alunos em relação a projetos e atividades da escola. (HOPMANN; NESJE, 2002)

Embora o White Paper n. 37 (1990-1991) também tenha introduzido a necessidade de um sistema de avaliação nacional, este somente se tornou uma realidade após mais de dez anos. Em linha com a prática institucional, a apresentação deste White Paper levou a um longo debate acerca dos potenciais riscos de um sistema de avaliação forte. Muitas novas iniciativas foram lançadas, resultando em amplo debate público acerca de como deveria ser esse sistema de avaliação, e transformando a avaliação externa em objeto de contenda.

Não foi senão após o primeiro relatório do PISA ser publicado em 2001 que os debates se alteraram. Após o segundo relatório do PISA, três anos depois, os resultados acadêmicos dos alunos se tornaram o ponto focal. Os debates se aceleraram e o Parlamento estava pronto para tomar uma decisão quanto a um sistema para avaliar a qualidade da educação nacional, que então se tornaria o NQAS.

\section{A segunda onda: um foco maior na liderança e responsabilização}

A segunda onda da NGP objetivava lidar com os problemas de fragmentação causados pelas iniciativas da primeira onda, por meio de um equilíbrio entre a centralização e a descentralização e por intermédio da introdução de uma gestão baseada em valores, de forma a aumentar o entendimento dos objetivos e normas coletivos. (CHRISTENSEN; LÆGREID, 2011) White Paper n. 30 
(2003-2004), Culture for Learning, lançado por um governo de coalizão liderado pelos conservadores, introduziu um novo modelo de governança para a educação com foco na desregulamentação, competição por eficiência, resultados da aprendizagem e responsabilização. Ao passo que os argumentos no White Paper n. 37 (1990-91) estavam ligados à organização interna e à estruturação do sistema educacional, os argumentos apresentados no White Paper n. 37 (1990-91) diziam respeito aos desafios do mundo globalizado aos quais o sistema educacional deveria responder. Defende-se que o novo modelo de governança foi motivado pelas problemáticas descobertas do PISA e as preocupaçóes com a redução de disparidades nos resultados educacionais entre diferentes grupos sociais. As descobertas problemáticas do PISA são mencionadas 17 vezes neste documento, sustentando os argumentos a favor de mudanças, enquanto que o estudo Civic, que demonstrou que os alunos noruegueses tiveram uma pontuação muito alta em conhecimentos sobre democracia, foi mencionado apenas duas vezes, de forma bem passageira. O White Paper afirma que a igualdade e a excelência poderiam ser melhor atingidas por meio de uma forma de trabalho diferente dentro do sistema educacional, e que as escolas são reconhecidamente os instrumentos de mudança econômica e social. Em seu prefácio, a Ministra da Educação e Pesquisa, Kristin Clement, coloca a aprendizagem e a liderança no cerne da educação:

Nós devemos nutrir e desenvolver os melhores aspectos das
escolas norueguesas e, ao mesmo tempo, torná-las melhor
equipadas para atender os desafios de uma sociedade baseada no
conhecimento. Nossa visão é criar uma cultura melhor para a
aprendizagem. Se desejamos ser bem-sucedidos, nós devemos
ser mais capazes e mais dispostos a aprender. As escolas em
si devem se tornar organizaçóes de aprendizagem. Somente
então elas poderão oferecer empregos atrativos e estimular a
curiosidade dos alunos e motivá-los a aprender. As escolas
não podem nos ensinar tudo, mas elas podem nos ensinar a
aprender. (White Paper n. 30, 2003-2004, ênfase e tradução
dos autores)

De acordo com os argumentos apresentados neste documento, é patente o que os professores e os dirigentes das instituiçóes escolares precisam realizar um trabalho melhor do que antes, e eles devem ser mais capazes e dispostos. (MØLLER, 2007) Isso indica a noção de que antes as escolas haviam falhado em alguns aspectos importantes. O NQAS foi, portanto, implantado para ajudar as escolas a atingir seus objetivos. Também foi realizada uma conexão explícita entre a aprendizagem e a liderança:

Para que as escolas sejam capazes de realizar isso, é necessário mudar o sistema segundo o qual elas são administradas e conduzidas. [...] Todos os planos para o desenvolvimento e a 
melhoria das escolas falhará sem professores e diretores competentes, compromissados e ambiciosos. Eles são os ativos mais importantes do sistema escolar. (White Paper n. 30, 2003-2004, cap. 1, tradução dos autores).

A fim de fazer bom uso do conhecimento produzido pelo NQAS, cada escola precisa de líderes (ou dirigentes) ambiciosos, com atitudes positivas em relação à mudança e ao aprimoramento. Os argumentos que subjazem um foco na liderança são legitimados por meio da referência a estudos internacionais de forma geral, sem que haja referência a estudos específicos:

Uma organização de ensino precisa de uma forte liderança que transmita expectativas explícitas com relação aos propósitos e objetivos da escola. Toda a experiência mostra que a liderança é a chave para o desenvolvimento bem-sucedido na escola. [...] Há inúmeros estudos internacionais que demonstram o que sabemos sobre como uma liderança escolar bem sucedida pode melhorar as escolas. [...] Os dirigentes escolares em escolas que estão se aperfeiçoando conseguem construir organizaçóes de aprendizagem. (White Paper n. 30, 2003-2004, cap. 3.3.3 e 3.4.2, ênfase e tradução dos autores)

O principal argumento, neste relatório, é que uma liderança forte é necessária para transformar as escolas em organizaçóes de aprendizagem. Em contraste, o relatório desaprova o que chama de "dirigentes condescendentes" que "[...] estão transferindo aos professores sua responsabilidade pela aprendizagem dos alunos. Eles estão relutantes em iniciar diálogos com os professores acerca de como a educação poderia ser aprimorada [...]". (White Paper n. 30, 20032004, cap. 3.4.1, tradução dos autores) Ao passo que a liderança condescendente contribui para o fracasso, uma liderança forte é uma promessa de sucesso. Uma liderança complacente cria um obstáculo para a melhoria da escola e para o desenvolvimento de organizaçóes de aprendizagem, enquanto uma liderança visível pode trazer contribuiçóes importantes para melhorar a aprendizagem dos alunos.

Ao mesmo tempo, a autonomia local é destacada por todo o relatório, conforme pode ser exemplificado pela citação a seguir:

A ideia de que o Estado pode prover uma educação equitativa por meio da regulação detalhada é substituída pela confiança de que o professor, o diretor e o município são capazes de criar boas oportunidades de aprendizagem dentro do quadro dos objetivos nacionais. (White Paper n. 30, 2003-2004, p. 25, tradução dos autores) 
No entanto, a autonomia local também foi usada como argumento para fortalecer o papel de supervisão do Estado em termos da introdução de um aparato de inspeção do Estado para assegurar que os municípios cumprissem suas responsabilidades de acordo com o Ato da Educação e os direitos legais dos alunos. Esse elemento estava ligado à reestruturação da administração educacional do Estado e à decisão de estabelecer a Diretoria Norueguesa para a Educação e a Formação, que seria responsável pela implementação da política educacional nacional. A Diretoria teria responsabilidade geral pela inspeção, mas a tarefa concreta foi delegada às secretarias de educação regionais. O White Paper n. 30 afirma que esta supervisão dos municípios por parte do Estado "[...] requer informação e abertura sobre a competência das escolas em alcançar os objetivos [...]". (White Paper n. 30, 2003-2004, p. 26, tradução dos autores) O governo também introduziu um site, o 'Skoleporten' (o Portal da Escola), como um banco de dados no qual os resultados de testes nacionais e outras estatísticas educacionais poderiam ser publicados.

A reforma educacional recente, intitulada a Promoção do Conhecimento, foi desenvolvida com base nos princípios apresentados no White Paper n. 30 (2003-2004). Ela foi iniciada por um governo de coalizão liderado pelos conservadores, mas lançada e implantada pelo governo de coalizão vermelho-verde (que inclui o Partido de Esquerda Socialista, o Partido Trabalhista e o Partido Centrista) que assumiu o poder em 2005. Os objetivos relativos a conteúdo do currículo nacional foram reformulados como competências, que são mais fáceis de serem avaliadas. (SIVESIND; BACHMANN, 2008) A mensuração do desempenho, os padróes e a responsabilização se tornaram parte da reforma educacional.

Como tal, a implantação da reforma Promoção do Conhecimento exemplifica a tradição da política de busca de consenso na educação norueguesa. Tanto os partidos de direita quanto de esquerda buscaram o compromisso e o acordo na reforma educacional. Ao mesmo tempo, o nível regional tem sido central e, durante toda a história, o nível municipal tem desempenhado um forte papel junto à tradição de implantação vinda de cima. (MØLLER, 2009) Contudo, as tensóes entre os governos central e locais aumentaram nos últimos dez anos. Citaçóes de dois ex-ministros da Educação e Pesquisa podem ilustrar tal tensão. Em 2002, a Ministra Kristin Clemet, representante do Partido Conservador, em um governo de coalizão liderado pelos conservadores anunciou: "Nós temos que impulsionar a descentralização, melhorar o controle de qualidade e aumentar a influência dos usuários. A escola será governada de baixo, e não de cima, porém dentro dos padrōes traçados em nível nacional [...]”. (MINISTÉRIO DA EDUCAÇÃO E PESQUISA, 2002, p. 2, tradução dos autores)

Em 2007, o Ministro Bård Vegar Solhjell, representando o Partido da Ala Esquerdista, em um governo de coalizão vermelho-verde, declarou em uma conferência nacional de líderes escolares: 
Eu fico chateado quando vejo os resultados da Inspeção Nacional em 2006 e 2007. [...] 70\% dos municípios não atingiram os requisitos de ter um sistema adequado de leis e regulamentaçóes para o monitoramento. [...] Nós nos deparamos com muitas discussóes importantes sobre como fortalecer as escolas dentro de um sistema descentralizado.

O White Paper n. 31 (2007-2008), Quality in Schools (Qualidade nas Escolas), publicado pelo governo de coalizão vermelho-verde declara: "O Governo deseja maior controle nacional da escola, mas também irá requerer e dar apoio a uma governança local mais forte [...]". (White Paper n. 31, 2007-2008, p. 11) Os argumentos a favor da recentralização e gestão mais forte vinda de cima foram fortalecidos quando o Ministro Solhjell, em uma entrevista a um jornal, argumentou: "Temos que impor mais rigor à agência local, pois a escola e o conhecimento não são assuntos locais [...]”. (SOLHJELL, 2009, tradução dos autores)

\section{Discussão}

As características em comum da reforma da NGP incluem, conforme mencionado na introdução, a desregulamentação, descentralização, flexibilidade organizacional e um ethos empresarial caracterizado pela competição e mercado. No contexto da educação norueguesa, a NGP inclui um foco particular na descentralização e na GPO. Mais tarde identificamos um forte foco na liderança e governança da escola por meio de resultados. Ao examinarmos a relação entre essas ideias gerencialistas e como a governança da escola e a liderança são concebidas no contexto norueguês, três áreas de luta discursiva podem ser identificadas. A primeira está ligada às ideologias e à história nacional de escolarização. A segunda está associada a aspectos controversos do profissionalismo docente. A terceira está relacionada a estratégias de modernização e melhoria na qualidade da educação.

A análise dos documentos da política norueguesa revela, ao menos no âmbito discursivo, que os elementos da reforma se pautaram por estratégias de resposta ao usuário, ao invés de estratégias de competição e mercantilização. Como mencionado anteriormente, a população na Noruega é extremamente dispersa, e a sobrevivência das inúmeras pequenas comunidades depende da escola que, em muitos locais, representa um centro cultural. Igualmente, um sistema educacional abrangente ainda está fortemente enraizado nas ideologias e normas, enfatizando vários aspectos de igualdade que estão ligados aos valores da social-democracia e de participação e, a importância de se prover acesso igualitário à educação independentemente da localização geográfica, do gênero, origem social ou cultural ou habilidade, é enfatizada. Essas normas e valores contrastam com alguns dos elementos enfatizados nas reformas da NGP, tais como privatização, 
competição e mercado. Tendo em vista que o sistema educacional norueguês é predominantemente público, esses elementos terão pouca influência. Como tal, as estratégias receptivas ao público, enquanto elementos da reforma, melhor se encaixam nesse contexto.

Um assunto a respeito do qual os partidos políticos noruegueses discordam é em que medida a privatização poderia ser permitida de forma a melhorar a competitividade entre as escolas. Um exemplo recente das iniciativas da reforma da NGP que tem sido recuada inclui mudanças na lei acerca de escolas privadas. Uma proposição que torna mais fácil abrir escolas privadas com apoio de fundos públicos foi promovida quando a coalizão conservadora estava no poder em 2004 , mas, imediatamente após a coalizão dos partidos social-democrata e de esquerda assumirem o poder em 2005, a lei foi alterada. (HANSEN, 2011) Desde entáo, os procedimentos para a aprovação de escolas privadas tem sido estritamente regulada, e há baixos níveis de manobra na interpretação da lei. Alguns municípios tentaram promover maior privatização de escolas, mas aprenderam que precisam submeter-se ao governo central. No entanto, em alguns dos municípios maiores, por exemplo, Oslo, as escolas de ensino médio superior precisam competir para atrair os alunos mais talentosos.

O monitoramento dos resultados educacionais foi inicialmente adicionado à agenda pública na Noruega após a revisão da OCDE em 1988. Esse monitoramento é também um elemento chave no quadro geral da NGP, mas, geralmente, durante os anos 1990, a Noruega podia ser descrita como relutante sobre o novo gerencialismo. (CHRISTENSEN; LÆGREID, 2011) No entanto, quando os resultados do PISA foram anunciados, os debates se alteraram e os resultados acadêmicos dos alunos se tornaram o ponto focal. O discurso acerca de tornar os professores responsáveis se tornou mais persistente e pressionador. Muito embora a autonomia profissional ainda fosse enfatizada, houve uma guinada a respeito de como a confiança nos professores era comunicada quando o NQAS foi introduzido. Esse discurso também incluía a liderança forte como um veículo para o projeto de modernização da educação e, como tal, reconfigurou as relações hierárquicas nas escolas e redefiniu os professores enquanto seguidores. Mais de uma década após a construção dos regimes de responsabilização no Reino Unido, mudanças semelhantes passaram a ocorrer na Noruega, embora, até o momento, seja um regime de teste com baixo interesse. Porém, houve uma mudança para um tipo de governança mais orientado aos resultados, e foram tomadas medidas para introduzir a desregulamentação no setor público. (MØLLER; SKEDSMO, 2013)

Em certa medida isso reflete uma mudança nos valores da sociedade. Contudo, as formas mais tradicionais de governança nacional na educação, tais como as diretrizes curriculares, não estão sendo substituídas. Ao contrário, como resultado de um foco maior nos resultados dos alunos, formas de governança orientadas por insumo estão sendo incluídas nos sistemas de garantia da qualidade 
e de responsabilização (accountability). Em anos mais recentes, vários programas que objetivam melhorar o desempenho dos alunos foram lançados em âmbito nacional. Esses programas são diferentes no que tange a quão estreitas são as vinculaçóes entre as expectativas e os resultados. (SKEDSMO, 2009) Um exemplo disso é o programa de desenvolvimento escolar nacional "From Words to Deeds" (De Palavras a Açóes), lançado em 2006, juntamente com a reforma mais recente, a Promoção do Conhecimento. O programa De Palavras a Açóes fornece fundos para o desenvolvimento de programas destinados a melhorar "a habilidade de avaliar os resultados e melhorar a prática escolar de acordo com os objetivos na Promoção do Conhecimento". (The Norwegian Directorate of Education and Training, 2007)

Embora a análise dos documentos evidencie que a igualdade e a cidadania ainda são elementos chave nas diretrizes do currículo nacional, as ideias gerencialistas, vinculadas à tendência de globalização no que concerne a perseguição da competição bem-sucedida na nova economia do conhecimento, estão exercendo forte influência na maneira pela qual os municípios organizam e gerem as escolas na Noruega. Isso ocorre independentemente de o governo local ser uma coalizão de partidos de direita ou representantes de partidos da social-democracia e de esquerda. Em muitos casos, o líder de nível intermediário (o Chief Education Officer) do antigo modelo tem sido deixado de fora. Ao invés de haver um departamento com um superintendente centrado particularmente em assuntos relacionados às escolas, a reestruturação implicou a responsabilidade conjunta entre cultura, escolas e formação. Os argumentos a favor da alteração são geralmente baseados em pesquisas realizadas por economistas, nas quais a educação é concebida como uma função de produção, e a análise é baseada na teoria agente-principal, que assume que os agentes são autointeressados e racionais. Com base em tais estudos, argumenta-se que a desregulamentação irá reduzir a burocracia e que os professores devem ser sujeitos a monitoramento e avaliação externos, de forma a aumentar a eficácia. (WÖßMANN, 2001; HANUSHEK; RAYMOND, 2005) Paradoxalmente, as mudanças levaram, em muitos casos, a estruturas administrativas mais hierárquicas e aumentaram a centralização de tarefas e da autoridade no âmbito municipal. Ainda mais importante, os municípios perderam pessoal com expertise no campo da educação (ENGELAND, 2000; FINSTAD; KVÅLE, 2003) Aqueles que trabalham com a educação, tanto no âmbito da escola quanto no âmbito do município, relatam o aumento da burocracia. (AASEN et al., 2012)

De forma parcialmente independente das reformas da NGP, há uma tendência crescente na judicialização na educação, e os direitos dos usuários são frequentemente associados a leis e regulamentaçóes. Tanto as autoridades locais como as escolas interagem com os pais e alunos que podem estar bem informados e conhecer bem os seus direitos. Na Noruega, as escolas são reguladas por mais de 400 regras e regulamentos, e os diretores das escolas devem conhecer a lei e serem capazes de observar seu papel de servidores públicos. Eles devem ancorar e justifi- 
car as práticas com base no Ato Educacional. A documentação é pré-requisito para a responsabilização (ou prestação de contas) pois, a fim de ser passível de prestação de contas, algo precisa ser apurado. Embora algumas áreas sejam rigorosamente reguladas, outras áreas deixam alguns aspectos abertos à interpretação.

Enquanto um programa de modernização para o setor público, a NGP inclui dois projetos paralelos, porém não idênticos. $\mathrm{O}$ primeiro é geralmente vinculado aos partidos conservadores e enfoca a transformação do setor público em um setor mais eficaz e eficiente ao estabelecer mecanismos de mercado, como a competição, a privatização e a terceirização, com base na crença de que aqueles que trabalham no setor público então darão o melhor de si para atender a um bem comum. O segundo projeto está relacionando ao estabelecimento de unidades em níveis inferiores da hierarquia pública, que sejam responsáveis por resultados específicos, e à profissionalização da liderança. $\mathrm{O}$ segundo projeto não entra, necessariamente, em conflito com o legado da escola comum para todos como um princípio de oportunidade igualitária à educação, e parece ter apoio total tanto dos partidos de esquerda como de direita. Ambos os projetos objetivam a redução da burocracia e tornar a governança mais eficaz e eficiente e, como tal, é possível que a governança democrática seja sacrificada no altar da eficiência.

\section{Resumindo}

Neste artigo nós examinamos a maneira pela qual as reformas da NGP são moldadas, traduzidas e adaptadas no setor educacional na Noruega. Nós apontamos que, na Noruega, os componentes da NGP foram introduzidos em duas ondas, como parte dos programas de modernização do setor público em geral e, principalmente, no que tange ao governo local. No setor educacional, os componentes da primeira onda produziram consequências, sobretudo na reestruturação da administração escolar local em termos de desregulamentação, especialização horizontal e gestão por objetivos. Exemplos de iniciativas que podem ser vistas como parte da segunda onda são o estabelecimento do NQAS e a reforma mais recente, a Promoção do Conhecimento. Esses representam iniciativas de coordenação centralizadas que almejam equilibrar os elementos descentralizadores e aplicar formas de governança mais orientadas a resultados, em combinação com formas orientadas por insumos. Este movimento representa movimentos internacionais e globais relacionados com a competição na educação e com a economia que não pertencem à NGP, embora as ideias nas quais se baseiam possam ser correspondentes.

Com base em nossos estudos dos documentos selecionados e pertencentes às duas últimas décadas, mostramos como a NGP tem sido intimamente ligada à introdução da GPO no setor educacional na Noruega e como alguns elementos 
das reformas da NGP são adaptados devido ao fato de o sistema educacional ser predominantemente público. A compreensão da regulamentação também é influenciada por uma história longa e forte de regulamentação nacional da educação em termos de amplas diretrizes curriculares e regulamentação por lei. No entanto, juntamente com uma regulamentação forte parece haver altos níveis de brechas na interpretação dos elementos das reformas da NGP. Tendo em vista tais aspectos, as tensôes entre uma regulamentação forte e uma regulamentação fraca podem sustentar uma margem de manobra na interpretação das políticas por parte dos profissionais.

A NGP não alterou diretamente a tradição educacional estabelecida, uma vez que foi introduzida de forma mais indireta. No entanto, o desenvolvimento da NGP mudou de direção e foi acelerado durante a segunda onda, quando a Noruega foi listada entre os países com "baixo desempenho" de acordo com o PISA e outros testes internacionais. A responsabilização e a liderança escolar se tornaram assunto no debate público. Antes das reformas, o público e os pais tinham, acima de tudo, confiança nos profissionais, mas agora a atenção está sendo cada vez mais voltada à confiança no que pode ser mensurado por resultados. A análise neste artigo foi inspirada por teorias institucionais e, como regra geral, tais perspectivas podem ser resistentes à imagem de pontos de viragem. Ao invés de rompimentos bruscos, é mais comum destacar a evidência de continuidades. Contudo, a relação entre a NGP e a publicação dos resultados do PISA no contexto norueguês pode vir a ser uma exceção.

Desta forma, argumentamos que a formulação das responsabilidades das autoridades e lideranças educacionais mudaram em documentos recentes. $\mathrm{O}$ foco na mensuração "objetiva" tem colocado a educação em maior aproximação com o progresso e desempenho econômico na Noruega, embora o ponto inicial para o desenvolvimento da NGP na Noruega não tenha sido a competição, mercantilização ou escolha individual. No entanto, há vários paradoxos ligados às razóes fundamentais por detrás das recentes reformas na educação. Primeiramente, enquanto as reformas da NGP objetivem reduzir a burocracia e tornar a governança mais eficaz e eficiente, aqueles que trabalham no setor educacional, tanto no âmbito municipal como escolar, têm vivenciado um aumento na burocracia. Em segundo lugar, enquanto a Noruega detém pontuação internacional baixa em leitura, Ciências e Matemática nos testes internacionais do PISA, há outros fatores que sugerem que a Noruega está se saindo muito bem na educação. Por exemplo, os estudantes noruegueses possuem pontuaçôes altas no estudo internacional CIVIC, e as escolas são menos segregadas do que em muitos outros países. Além disso, as taxas de letramento adulto e os índices de saúde e bem-estar são bem altos. (STATISTICS NORWAY, 2012) Por fim, os perigos de um sistema com baixo desempenho para a economia de uma nação, conforme medido pelos testes 
do PISA, tem sido fortemente discutido em debates públicos mas, ao mesmo tempo, a Noruega possui uma das economias mais fortes no mundo.

\section{Notas}

1. Traduzido por Karin Quast.

2. A responsabilidade geral pela supervisão das escolas é delegada aos Gabinetes Educacionais Regionais (18 no total). Os 430 municípios na Noruega são responsáveis por 10 anos de educação obrigatória, cobrindo o ensino fundamental e parte do ensino médio. Os municípios variam em tamanho bem como no nível de bem-estar.

3. N.T.: As citaçōes desses documentos foram traduzidas do norueguês para o inglês (e então para o português) porque tais documentos não estão disponíveis em inglês.

\section{Referências}

ANTIKAINEN, A. In search of the nordic model in education. Scandinavian journal of educational research, v. 50, n. 3, 2006, p. 229-243.

BALL, S. J. Education reform. A critical and post-structural approach. Buckingham: Open University Press, 1994.

CHRISTENSEN, T. Virksomhetsplanlegging. Myteskaping eller instrumentell problemløsing? Oslo: Tano, 1991. [Management by objectives. Creating myths or solving problems instrumentally?].

CHRISTENSEN, T.; LÆGREID, P. NPM and beyond: leadership, culture, and demography. Bergen: Rokkansenteret, 2007.

. Beyond NPM? Some development features. In: (Eds.). The Ashgate research companion to new public management. Farnham, England: Ashgate Publishing Ltd., 2011, p. 391-403.

CLARKE, J.; NEWMAN, J. Public, politics \& power. Remaking the public in public services. London: Sage, 2009.

ENGELAND, Ø. Skolen i kommunalt eie - politisk styrt eller profesjonell ledet skoleutvikling? Doktorgradsavhandling. Det utdanningsvitenskapelige fakultet: Universitetet i Oslo, 2000. ESPING-ANDERSEN, G. Three worlds of welfare capitalism. Cambridge, England: Polity Press, 1990.

FAIRCLOUGH, N. Discourse and social change. Cambridge, England: Polity Press, 1992.

FINSTAD, N.; KVÅLE, G. Reform 97 - skolen og kommunen. Bodø: Nordlandsforskning, 2003. [Reform 97 - the school and the municipality]. 
GUNDEM, B. B. Mot en ny skolevirkelighet? Lareplanen i et sentraliserings- og desentraliseringsperspektiv. Oslo: Ad Notam Gyldendal, 1993. [Towards a new school reality? Curriculum seen from centralisation-decentralisation persepective].

HANSEN, H. F. NPM in Scandinavia. In: CHRISTENSEN, T.; LÆGREID, P. (Eds.). The Ashgate research companion to new public management. Farnham, England: Ashgate Publishing Ltd., 2011, p. 113-129.

HANUSHEK, E. A.; RAYMOND, M. E. Does school accountability lead to improved Student Performance? Journal of policy analysis and management, v. 24, n. 2, 2005, p. 298-327.

HOMME, A. Den kommunale skolen. Det lokale skolefeltet i historisk perspektiv Doktorgradsavhandling. Institutt for administrasjon og organisasjonsvitenskap. Bergen: Universitet i Bergen, 2008.

HOOD, C. Intellectual obsolescene and intellectual makeovers: reflections on the Tools of Government after Two Decades. Governance: An international journal of policy, administration, and institutions, v. 20, n. 1, 2007, p. 127-144.

HOPMANN, S.; NESJE, K., Innledning [Introduction]. In: NESJE, K.; HOPMANN, S. (Eds.). En larende skole. L97 i skolepraksis. Oslo: Cappelen Akademisk Forlag, 2002, p. 9-24. [A learning school. The Curriculum guidelines of 1997 in practice].

KARLSEN, G. Desentralisert skoleutvikling. En utdanningspolitisk studie av norsk grunnskole med vekt på 70- og 80-tallet. Oslo: Ad Notam Gyldendal, 1993.

KLAUSEN, K. K. Skulle det vare noget sarligt? Copenhagen: Børsen, 2001. [Is that supposed to be special?].

LAWN, M.; GREK, S. Europeanizing education. Governing a new policy space. Oxford, UK: Symposium Books, 2012.

MAHONEY, J.; THELEN, K. Explaining institutional change. Ambiguity, agency, and power. Cambridge: Cambridge University Press, 2010.

MAUSETHAGEN, S.; GRANLUND, L. Contested discourses of teacher professionalism: current tensions between education policy and teachers' unions. Journal of education policy, v. 27, n. 6, 2012, p. 815-833.

MINISTRY OF EDUCATION. RESEARCH AND CHURCH AFFAIRS. White Paper $n$. 37, Om organisering og styring av utdanningssektoren. Oslo: Ministry of Education, 1990-91. [About the organization and management of the education sector].

MINISTRY OF EDUCATION AND RESEARCH. Skolen vet best Report. Oslo, 18 nov. 2002.

. White Paper n. 30, Kultur for laring, 2003-2004. [Culture for learning].

. White Paper n. 31, Kvalitet i skolen, 2007-2008. [Educational quality].

MØLLER, J. Democratic schooling in Norway: Implications for leadership in practice. leadership and policy in schools. International perspectives on leadership for social justice, v. 5, n. 1, 2006, p. 53-69. 
MØLLER, J. Educational leadership and the new language of learning. International journal of leadership in education, v. 10, n. 1, 2007, p. 31-49.

. Approaches to school leadership in Scandinavia. Journal of educational administration and history, v. 41, n. 2, 2009, p. 165-177.

MØLLER, J.; SKEDSMO, G. Modernising education: New Public Management reform in the Norwegian education system. Journal of Educational Administration and History, v. 45, n. 4, 2013, p. 336-353.

NESPOR, J. Networks and contexts of reform. Journal of educational change, v. 3, n. 4, 2002, p. 365-382.

NORWEGIAN DIRECTORATE OF EDUCATION AND TRAINING. Oppdragsbrev 2007 (Instructions 2007). Available: <http://udir.no/upload/skoleutvikling/Oppdragsbrev 2007.pdf $>$. Accessed 18 june 2012.

. The education mirror: analysis of primary and secondary education and training in Norway. A Available: <http://www.udir.no/Tilstand/Utdanningsspeilet/Education-Mirror/The-Education-Mirror-2011/>. Accessed 18 aug 2012.

OECD. Reviews of National Policies for Education Norway. Paris: OCDE/Department of the Examiners, 1988.

OZGA, J.; JONES, R. Travelling and embedded policy: the case of knowledge transfer. Journal of education policy, v. 21, n. 1, 2006, p. 1-17.

PETERS, G.; PIERRE, J. (Eds.). Handbook of public administration. 2. ed. London: Sage, 2005.

POLLITT, C.; BOUCKAERT, G. Public management reform. A comparative analysis. 2. ed. New York: Oxford University Press, 2004.

SIVESIND, K. Reformulating reform. Curriculum history revisited. Thesis ( $\mathrm{PhD}$ in Education) - Faculty of Education, University of Oslo, 2008.

SIVESIND, K.; BACHMANN, K. Hva forandres med nye standarder? Krav og utfordringer med Kunnskapsløftets læreplaner. In: LANGFELDT, G.; ELSTAD, E.; HOPMANN, S. (Eds.). Ansvarlighet i skolen. Politiske spørsmål og pedagogiske svar. Fagernes: Cappelen Akademisk Forlag, 2008, p. 62-93.

SKEDSMO, G. School governing in transition? Perspectives, purposes and perceptions of evaluation policy. Thesis (PhD in Education) - Faculty of Education, University of Oslo, 2009.

SOLHJELL, B. Interview with Minister Solhjell. Dagsavisen, Oslo, may 22, 2009.

SØREIDE, G. E. The public face of teacher identity - narrative construction of teacher identity in public policy documents. Journal of education policy, v. 22, n. 2, 2007, p. 129-146.

STATISTICS NORWAY. Facts about education in Norway 2012: Key figures 2010. Available: <http://www.ssb.no/english/subjects/04/02/facts/>. Accessed: 15 aug 2012. 
Nova gestão pública na Noruega

TRANVIK, T.; FIMREITE, A. L. Reform failure. The processes of devolution and centralisation in Norway. Local government studies, v. 32, n. 1, 2006, p. 89-107.

WÖßMANN, L. Why students in some countries do better: international evidence on the importance of education policy. Education matters, v. 1, n. 2, 2001, p. 67-74.

Recebido em 21 de julho de 2015.

Aprovado em 28 de setembro de 2015.

DOI: http://dx.doi.org/10.1590/ES0101-73302015152510 